\title{
Médiévales
}

Langues, Textes, Histoire

81 automne 2021

Voix laïques (XIe-XIIIe siècle)

\section{Barbara Gelli, Fra principi, mercanti e partegiani. Francesco Aringhieri politico e diplomatico senese del Quattrocento}

Pise, Pacini (Biblioteca della « Miscellanea storica della Valdelsa », 32), 2019, 376 p.

Didier Boisseuil

\section{OpenEdition}

\section{Journals}

Édition électronique

URL : https://journals.openedition.org/medievales/11978

DOI : 10.4000/medievales. 11978

ISSN : $1777-5892$

Éditeur

Presses universitaires de Vincennes

Édition imprimée

Date de publication : 12 janvier 2022

Pagination : 205-206

ISBN : 978-2-37924-202-1

ISSN : 0751-2708

Référence électronique

Didier Boisseuil, « Barbara Gelli, Fra principi, mercanti e partegiani. Francesco Aringhieri politico e diplomatico senese del Quattrocento », Médiévales [En ligne], 81 | automne 2021, mis en ligne le 28 janvier 2022, consulté le 22 avril 2022. URL : http://journals.openedition.org/medievales/11978 ; DOI : https://doi.org/10.4000/medievales.11978

Ce document a été généré automatiquement le 22 avril 2022

Tous droits réservés 


\section{Barbara Gelli, Fra principi, mercanti e partegiani. Francesco Aringhieri politico e diplomatico senese del Quattrocento}

Pise, Pacini (Biblioteca della « Miscellanea storica della Valdelsa », 32), $2019,376 \mathrm{p}$.

Didier Boisseuil

\section{RÉFÉRENCE}

Barbara Gelli, Fra principi, mercanti e partegiani. Francesco Aringhieri politico e diplomatico senese del Quattrocento, Pise, Pacini (Biblioteca della « Miscellanea storica della Valdelsa », 32), 2019, $376 \mathrm{p}$.

1 En étudiant les origines et la carrière politique d'un puissant citoyen siennois du $\mathrm{xv}^{\mathrm{e}}$ siècle, Barbara Gelli nous offre, non pas une simple biographie d'un illustre inconnu, mais une véritable et profonde réflexion sur le fonctionnement d'une république urbaine à l'aube de la Renaissance. Nourrie des approches les plus contemporaines sur la construction de l'État et l'essor de la diplomatie, analysant finement une abondante documentation archivistique toscane - et dans une moindre mesure romaine et vénitienne - l'auteure révèle, à hauteur d'homme, les pratiques, les stratégies, les évolutions du groupe dominant de la cité de la Vierge pour maintenir, malgré les ambitions de puissances rivales, l'autonomie du plus " petit des grands États » de la péninsule. Après avoir retracé l'origine de la famille - issue d'une communauté du contado, aux confins du territoire florentin (Casole val d'Elsa) - dans le contexte siennois du Trecento, encore féodal et communal, Barbara Gelli s'attarde sur la formation humaniste du jeune Aringhieri, organisée avec soin dans son réseau familial étendu, par ses parents proches et notamment sa mère. Cette formation fut essentielle, car elle lui permit de s'adapter aux vicissitudes de la vie politique siennoise. Barbara Gelli montre aussi que, contraint de s'exiler à Venise, Francesco sut mettre à profit les 
soutiens des amis de son père pour amorcer une activité commerciale et bancaire qui lui permit d'acquérir, sur les bords de la lagune, au côté d'autres Toscans, non seulement une compétence reconnue, mais aussi la confiance des Vénitiens. Surtout, l'auteure révèle avec subtilité comment, de retour d'exil, son habileté diplomatique établie, Francesco fut envoyé comme ambassadeur auprès du duc de Milan et du roi de Naples et obtint de ces princes, à la fois la considération et la distinction (notamment le titre de chevalier) qui l'élevèrent au-dessus du reste de ses concitoyens, lui offrant la possibilité de compter parmi les hommes les plus influents de la cité. Ce rôle nécessitait une attention et des efforts constants pour s'assurer les soutiens et les suffrages de ses compatriotes, dont les réseaux nombreux et complexes articulaient la vie politique et économique de cette petite république dans et en dehors de murs de l'enceinte. Toutefois, c'est à Rome, auprès du pape, que Francesco connut l'apothéose de sa carrière en devenant sénateur. Cette fonction lui conférait une visibilité exceptionnelle et consacra son appartenance aux élites péninsulaires qui gravitaient autour du souverain pontife, lui donnant ainsi les moyens de consolider son prestige et sa fortune, et de veiller plus sereinement aux destinées de sa descendance. Elle renforçait aussi l'image du citoyen, paré des vertus antiques, dont la vie avait été dédiée à la chose publique. Car Francesco s'était désintéressé du commerce et revendiquait de ne vivre, à la fin de sa vie, que de ses rentes fondées sur un solide patrimoine foncier, établi par son père, dans le sud du territoire siennois, qu'il gérait avec soin. Cela ne signifiait pas cependant qu'il s'était complètement éloigné des affaires, puisque Barbara Gelli détaille les liens étroits qui l'unissaient aux banquiers et marchands siennois les plus actifs de l'Italie. La parabole qu'elle dresse avec une plume alerte et sûre permet d'apprécier de façon efficace, en multipliant les angles d'approche, la complexité du «laboratoire italien ", à l'aube des Temps modernes, loin des grandes métropoles (Milan, Venise, Naples, Florence et Rome), si souvent étudiées. Un grand livre qui s'inscrit dans la riche et stimulante tradition historiographique siennoise et qui rend justice au destin singulier de la cité de la Vierge.

\section{AUTEURS}

DIDIER BOISSEUIL

Université de Tours, Cethis 